\title{
ECONOMIC CONVERGENCE IN THE CONTEXT OF OVERCOMING THE INTRA-REGIONAL DISPARTIES IN BULGARIA
}

DOI: http://dx.doi.org/10.18509/GBP.2019.29

UDC: 330.35:339.97(497.2)

\author{
Nikolay Katsarski \\ Sofia University “St. Kliment Ohridski”, Faculty of Geology and Geography, \\ Department of Regional Development, Bulgaria
}

\begin{abstract}
The economic regional cohesion between the regional centers in Bulgaria is of utmost importance given the differences in the economic activity of the population and the business on the one hand. On the other hand, disproportion in terms of factors of production (resources, labor force, technical and transport infrastructure, innovation) and, above all, their unequal position in quantitative and qualitative terms. This publication aims to highlight the major issues that these disproportions are due to, and to provide recommendations for their overcoming in the future. The main flight problems relate mainly to the development of large cities. This determines Sofia as the leader in the highest share of the gross domestic product of the country. In addition, the development of the top ten big cities in Bulgaria creates conditions for the strengthening of the centerperiphery problems. Inter-regional and intra-regional inequalities and differences can also be highlighted in this connection.
\end{abstract}

Keywords: regional development, economic convergence,

\section{INTRODUCTION}

The need to strengthen the role of small towns is particularly important because of their depopulation and lack of development. Large and medium-sized cities could play the role of balancers. They should be supported in the maintenance and development of smaller towns. By building appropriate infrastructure, creating jobs, providing access to health and social services. This will provide the opportunity for decentralization and concentration of production factors not only to large cities but also to smaller ones. The competitiveness of cities in Bulgaria is extremely tangible in small towns. This is due to the small financial and staffing potential. The creation of conditions for the development of the sectors typical of the respective region and location is of particular importance. Detention of young people, their return after good education is also a priority to overcome regional disparities. State policy on the development of small and medium-sized cities also has its influence. Opportunities to apply for various projects at local, national and European level through state structures create favourable conditions for encouraging the development of these cities. The reason for seeking state intervention is that "almost all areas and districts are characterized by the characteristic center-periphery relations and the presence of lagging municipalities with little capacity and serious difficulties in their demographic, socio-economic and infrastructural development. "[1]

The impossibility of addressing regional imbalances also covers the lack of innovation and technical sufficiency of production factors. The morally outdated material and technical base, the scarcity of science centers to production facilities, and the everincreasing cost of consumables / electricity, water and materials, create prerequisites for 
delays in production capacities in remote settlements compared to district centers and large cities. This is also due to supply and demand, which is higher in the big cities. Greater consumption and realization of goods and services creates prerequisites for economies of scale. Low demand in small population areas is not able to realize these savings. This, in turn, is the next prerequisite for economic inequality.

Stimulating innovation and above all high technology does not require a large number of specialists, but rather highly qualified ones. Providing science centers in remote, big cities would result in overcoming regional disparities. Building such centers to small towns or low population segments will enhance the interest of businesses, will be an attractive center for groups of people who are interested in science and innovation. In addition, economic cohesion finds expression through the two-way science-business and businessscience link. The science-business relationship is expressed in the creation of new, experimental products to be offered to businesses for mass or limited sale. The other business-science link is realized by putting different business issues, interests, goals to find a scientific solution. The development of this bilateral relationship leads to the highest added value in competition between similar products.

Next, to consider the strengthening of the city-village connection. Cities around and villages play an important role in the development of production processes related to the cultivation of a number of crops, on the one hand. On the other hand, this can lead to the processing of raw materials into finished products. The emergence of factories and processing centers provides new jobs, the introduction of innovation and the improvement of the competitiveness of rural areas. In this way, the city-village link will intensify and economic disproportions will be limited. The loss of key positions in various areas of agricultural production over the years is subject to evaluation. This assessment enables the regions to benefit from different cultures. This also gives the possibility of convergence of certain regions in the wholesale trade by type of crops and plantations.

\section{ECONOMIC COHERENCE BETWEEN THE REGIONAL CENTERS IN BULGARIA.}

Economic, social and territorial cohesion is a key objective of the European Union (EU). The EU puts forward the spending of its budget to reduce disparities between regions. The main focus is on rural areas, industrial transition areas and those affected by adverse natural and demographic conditions. To achieve impartial spending, the following principles are respected

- Organisation of the funds by objectives and regions;

- Partnership between the Commission, Member States and regional authorities in planning, implementing and monitoring their use;

- Programming of assistance;

- Additionality of EU and national contributions.

- The allocation of the Union's financial resources devoted to cohesion policy is focused on two main goals:

- Investment for growth and jobs - aiming to strengthen the labour market and regional economies;

- European Territorial Cooperation - supporting EU cohesion through cooperation at cross-border, transnational and interregional level. [2] 
The application of the principles is achieved through the European structural and investment funds (ESF, ERDF, Cohesion Fund, European Agricultural Fund for Rural Development (EAFRD) and European Maritime and Fisheries Fund (EMFF)) and other sources such as the European Investment bank. The main problem in the EU is that there are differences - territorial, demographic, economic, etc. This hampers the simultaneous development of European countries on all the indicators. That is why the 1957 Treaty of Rome. has created two funds: the European Social Fund (ESF) and the European Agricultural Guidance and Guarantee Fund. This also marks the beginning of the overcoming of differences and disproportions in the community. The historical development of the funds has the following sequence:

Table 1. EU cohesion funds over the years

\begin{tabular}{|l|l|}
\hline Fund & year \\
\hline The European Social Fund (ESF) Gricultural Guidance and & 1957 \\
\hline $\begin{array}{l}\text { The European Agricul } \\
\text { Guarantee Fund }\end{array}$ & 1975 \\
\hline European Regional Development Fund (ERDF) & 1994 \\
\hline Cohesion Fund & \\
\hline
\end{tabular}

The Cohesion Fund is geared to strengthening economic, social and territorial cohesion in the EU for sustainable development. During the 2014-2020 programming period, the Fund finances primarily environmental, transport infrastructure, technical assistance and sustainable development activities. The eligibility criteria for funding are tied to Gross Domestic Product per capita. Within the 2014-2020 programming period, only 15 Member States meet the criteria and are: Bulgaria, Croatia, Cyprus, Czech Republic, Estonia, Greece, Hungary, Latvia, Lithuania, Malta, Poland, Portugal, Romania, Slovakia and Slovenia. They share 63.4 billion euros. With the lowest relative share of funding, Malta is 217.7 million. Euro, with Poland accounting for the highest share of 23,207.9 million. Euro. Bulgaria ranks 7th place with 2,278.3 million. Euro.

graphic 1 Member state budget in million euro /The data in the table was taken form [3]/

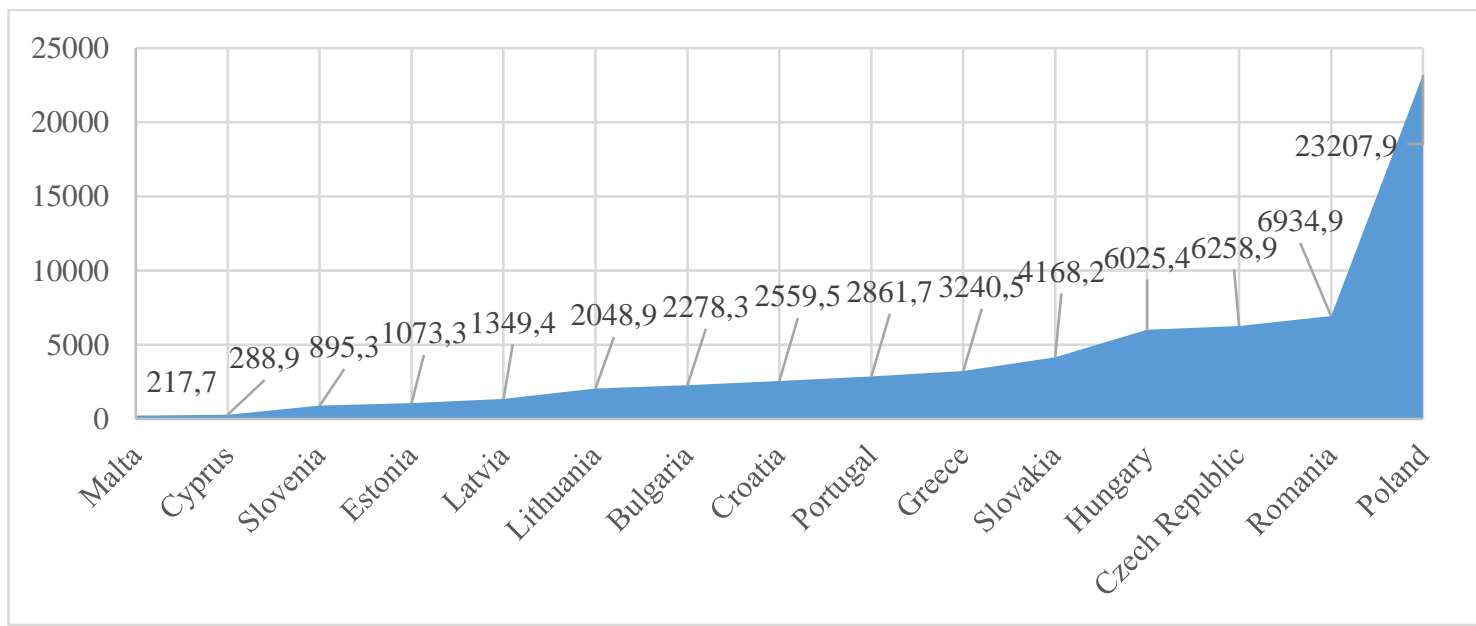

Figure 1. Member state budget (EUR milion)

In Bulgaria different priority axes for funding have been formed. They are divided into so-called priority axes. The focus is on Priority Axis 1 "Sustainable and Integrated Urban 
Development" and Priority Axis 2 "Supporting Energy Efficiency in Supporting Centers in Peripheral Areas". The essence of priority axis 1 is to improve the quality of life and economic growth in the cities in Bulgaria. This priority program covers 39 cities and aims to develop strategic development plans. They cover activities addressing economic, environmental, climatic, social and demographic problems in urban areas. In this regard, the beneficiaries have units with precisely defined functions, in order to qualitatively evaluate each project proposal. Funding options within this program are:

"Energy Efficiency" Activities: Implementation of energy efficiency measures in residential buildings, student hostels and administrative buildings of the state and municipal administration; Providing loans and / or guarantees for renovation of residential buildings and student hostels;

- "Integrated Urban Transport" Activities: Development of traffic management plans and introduction of Intelligent Transport Systems (ITS); Improvement of the accessibility of public transport stops and the infrastructure (underpasses and overpasses); Development and improvement of public urban transport systems, including the purchase of new rolling stock for the needs of urban transport;

- "Urban environment" activities: Construction and restoration of parks, green areas, playgrounds, zoos, city squares, inter-block spaces, open-air sports grounds, etc .; Construction and reconstruction of pedestrian alleys and sidewalks, construction of bicycle paths and alleys, pedestrian zones, subways, overpasses and bridges for pedestrians and cyclists; Installation of energy-saving street lighting and security and anti-crime systems;

- Activities for 'areas with potential for economic development': Improvement of existing or construction of new technical infrastructure related to business and entrepreneurship; Construction and renovation of business and industrial zones, incl. public or commercial buildings; Landscaping, recreation areas, bicycle lanes, bicycle and car parks for workers in economic zones;

- "Social infrastructure" activities: Support for the provision of modern social housing for the accommodation of vulnerable, minority and socially disadvantaged groups; Major repairs, construction and equipment of municipal infrastructure for provision of services for the elderly and people with disabilities; Major repairs, construction and equipment of appropriate municipal infrastructure to provide community-based services for children;

- "Cultural Infrastructure" Activities: Development of cultural infrastructure through the construction, reconstruction, renovation, equipment and furnishing of cultural centers, theaters, community centers, libraries, opera houses, galleries, cultural exhibition halls and other cultural institutions, including adjoining spaces;

- "Educational infrastructure" activities: Construction, reconstruction, renovation and equipment of municipal educational institutions;

- "Sports infrastructure" activities: Construction, reconstruction, repair, equipment and furnishing of sporting infrastructure for mass sports such as: sports halls, swimming pools, football playgrounds, stadiums for public use, combined volleyball and basketball playgrounds, tennis courts and etc. [4]

The main problem with the implementation of such activities is the numerous units and bureaucratic requirements and the many expert committees that often change their decisions. An example of this is the many infrastructure projects related to the construction of streets, roads and highways. Very often the control is not current and preliminary, but the follow-up is further complicating the implementation of the project activities. The other problem is related with human capital. In the administrative structure 
there are no policy for young people. Very often, there is a process of formal admission of trainees in some administrative structures, which takes place on the basis of their own rules, in the absence of a unified approach and the existence of different selection criteria.[5]

\section{COMPETITIVENESS AND INNOVATION.}

The convergence of individual Member States is of particular importance for the development of less developed economies. There is growing interest in Bulgaria as a destination for outsourcing activities. These are mainly activities in the field of finance, collection of receivables, call centers, etc. Another aspect of the Bulgarian business is that it consists mainly of staff up to 9 people. These are mostly small family businesses. In this respect, the expansion of activity, increasing the competitiveness of small traders is of particular importance. According to the National Statistical Institute (NSI) in 2015, the relative share of small enterprises with up to 9 people is $92.49 \%$ and in $2016-92.46 \%$, for $2017-92.48 \%$. This shows that their number is significantly higher than large companies. Another hypothesis that occurs in connection with these data is the excessive concentration of large companies only around major cities and centers. While smaller niches create a business niche for local merchants and entrepreneurs on the one hand. On the other hand, there may be a lack of investment interest from the big players on the market.

Table 2. the data was taken by National statistic institute

\begin{tabular}{|c|c|c|c|c|c|c|c|}
\hline & \multicolumn{2}{|c|}{2015} & \multicolumn{2}{|c|}{2016} & \multicolumn{2}{|c|}{2017} \\
\hline & & $\begin{array}{c}\text { Business } \\
\text { entities }\end{array}$ & Employees & $\begin{array}{c}\text { Business } \\
\text { entities }\end{array}$ & Employees & $\begin{array}{c}\text { Business } \\
\text { entities }\end{array}$ & Employees \\
\hline & & numbers & numbers & numbers & numbers & numbers & numbers \\
\hline \multirow{5}{*}{$\begin{array}{l}\text { Total for } \\
\text { Bulgaria }\end{array}$} & $\begin{array}{l}\text { Range of } \\
\text { employees }\end{array}$ & 393460 & 2101095 & 404937 & 2156511 & 406310 & 2193508 \\
\hline & from 0 to 9 & 363905 & 642068 & 375123 & 676993 & 375754 & 685704 \\
\hline & from 10 to 49 & 24264 & 480581 & 24500 & 485206 & 25211 & 498859 \\
\hline & from 50 to 249 & 4552 & 446961 & 4586 & 453068 & 4601 & 455516 \\
\hline & $250+$ & 739 & 531485 & 728 & 541244 & 744 & 553429 \\
\hline
\end{tabular}

Another point of the data presented is that in large enterprises of 10 to over 250 people work around $68-69 \%$ of the population. This is conditioned by the larger capital available to them, on the one hand. On the other hand, their ability to participate in different competitiveness programs is greater. In this respect, improving working conditions, wage increases, lower production costs and predictable tax policy are of particular importance. This is why European programs supporting regional cohesion are of particular importance.

Table 3. Data are processed as above

\begin{tabular}{|c|c|c|c|c|c|c|}
\hline \multirow[b]{2}{*}{$\begin{array}{l}\text { Range of } \\
\text { employees }\end{array}$} & \multicolumn{2}{|c|}{2015} & \multicolumn{2}{|c|}{2016} & \multicolumn{2}{|c|}{2017} \\
\hline & $\begin{array}{l}\text { Business } \\
\text { entities }\end{array}$ & Employees & $\begin{array}{l}\text { Business } \\
\text { entities }\end{array}$ & Employees & $\begin{array}{l}\text { Business } \\
\text { entities }\end{array}$ & Employees \\
\hline $0-9$ & $92.49 \%$ & $30.56 \%$ & $92.64 \%$ & $31.39 \%$ & $92.48 \%$ & $31.26 \%$ \\
\hline $10-250+$ & $7.51 \%$ & $69.44 \%$ & $7.36 \%$ & $68.61 \%$ & $7.52 \%$ & $68.74 \%$ \\
\hline
\end{tabular}

As the European regional development fund (ERDF) contributes to the Europe 2020 Strategy for smart, sustainable and inclusive growth, it has to focus on the priorities specified in this strategy. The main priorities are: 
- Research and innovation;

- Information and communication technologies (ICT);

- Small and medium-sized enterprises (SMEs);

- Promotion of a low-carbon economy.

The level of concentration required varies according to the category of regions being supported. More developed regions have to allocate at least $80 \%$ of their ERDF resources to at least two of these priorities and at least $20 \%$ to the low-carbon economy. Transition regions have to allocate at least $60 \%$ of their ERDF resources to at least two of these priorities and at least $15 \%$ to the low-carbon economy. Less developed regions have to allocate at least $50 \%$ of their ERDF resources to at least two of these priorities and at least $12 \%$ to the low-carbon economy.[6]

Other important instrument for developing the regions is the image. The image of the region is very important for the market. It can bring many new partnerships. The image of the region should be professionally managed through international, commercial, open or latent communication channels and technology to influence public opinion and target users to a region or product [7]. The image of the region can be different - positive or negative. That is why it is necessary to reflect those features of the region that are in line with the benefits for the region [8]. There are many problems which do not have any relationship with the image. The main problem is "possession of one's own home, which is a factor to stay at the same workplace longer"[9]. This problem may be solved with "with regional economic competitiveness; reducing interregional disparities; endogenous, balanced and sustainable development; addressing specific regional challenges; decentralization and regionalism and a multi-center territorial structure"[10]. Bulgarian economic reality always stands out with a high share of small companies. This is conditioned by craft activities over the centuries that our ancestors developed. That is why the presented principles will help the development of the Bulgarian economy and directly contrasted our regional development policy.

\section{CONCLUSION}

Economic cohesion is an essential element for the development of the Bulgarian economy. The main orientations of cohesion on science, innovation, the development of small and medium-sized businesses, information technologies are important for all economic sectors. Scientific and technological progress does not accidentally give the greatest added value in the development of new products and leads to cost optimization. Before that, however, the construction of appropriate infrastructure - manufacturing bases, highways, science centers, roads, etc., is urgent and should cover the whole country.

The development of small business is very often defined as the backbone of the economy, as there are mostly people employed in family businesses and small settlements. As presented in this article, they account for about $92 \%$ of businesses in Bulgaria. This is naturally dictated by the lack of a uniform investment policy in all centers. The factors for this are many and different, but the most important is the demographic problem and the lack of skilled labor. In this regard, attention should be paid not only to the villagecity connection, but also to large and small towns. 


\section{REFERENCES}

[1] The National Regional Development Strategy of the Republic of Bulgaria for the period 20122022.

[2] http://www.europarl.europa.eu/factsheets/en/sheet/93/economic-social-and-territorial-cohesion

[3] http://www.europarl.europa.eu/factsheets/en/sheet/96/cohesion-fund

[4] https://www.mrrb.bg/bg/infrastruktura-i-programi/operativna-programa-regioni-v-rastej/prioritetni-osi/

[5] Ivanov M., OPPORTUNITIES TO IMPROVE THE PROCESS OF LOCAL ECONOMIC DEVELOPMENT PLANNING, 5th SGEM International Multidisciplinary Scientific Conferences on SOCIAL SCIENCES and ARTS SGEM2018, 2018, doi:10.5593/sgemsocial2018/1.5/S05.092, Ref

[6] http://www.europarl.europa.eu/factsheets/en/sheet/95/european-regional-development-fund-erdf-

[7] Naydenov K1., REGIONAL IMAGE - A PREREQUISITE FOR ECONOMIC DEVELOPMENT http://mgu.bg/sessions/17/04/6-Kliment\%20Naydenov-2017.pdf

[8] Naydenov Kl., REGIONAL IMAGE - A PREREQUISITE FOR ECONOMIC DEVELOPMENT http://mgu.bg/sessions/17/04/6-Kliment\%20Naydenov-2017.pdf

[9] Metodi Ivanov, Influence of the instruments which reflecting regional differences in socioeconomic development of regions, 4th International Multidisciplinary Scientific Conference, Book 1, Volume IV , 2017, стр.423-431, doi:10.5593/sgemsocial2017/14

[10] Найденов Кл., Иванов М., Анализ и оценка на инвестиционната привлекателност и конкурентоспособност на регионите, РЕГИОНАЛНА ИКОНОМИКА И УСТОЙЧИВО РАЗВИТИЕ - 2017, 2018, стр.143-156, Ref 